\title{
Mental health services in the Seychelles
}

Rezaul Islam

When I reached Seychelles to start my new job with the Ministry of Health as a consultant psychiatrist at the Victoria Hospital I had hardly any idea about the islands, let alone its mental health service. But I decided to take the job partly out of curiosity and an interest to see what psychiatry would be on a tourist island in the middle of the Indian Ocean.

\section{The Seychelles}

The Seychelles is a beautiful island state with its granite and coral islands about the equator in the Indian Ocean. It has a population of about 73000 people living on the four main islands: Mahe Island, with the capital Victoria; Praslin the second largest; followed by La Digue; and Silhouette. According to census in $199430 \%$ of the population are less than 15 years old, while only $6 \%$ are aged 65 or more. The total land area is $445 \mathrm{~km}^{2}$. The climate is tropical with abundant vegetation throughout the year. The islands had no indigenous population until French colonists and African slaves settled in $\mathbf{1 7 7 0}$ and were later joined by small numbers of Indian and Chinese people (Fauvel, 1997). The Seychelles became independent from Britain in 1976, after being initially administered by France until 1814. The standard of living has improved markedly in recent decades. Gross domestic product (GDP) per capita increased from US\$ 600 in 1976 to US\$ 5850 in 1994, and the World Bank considers Seychelles to be a middle economy country at the present.

\section{Social background}

The ancestors of most Creole Seychellois were slaves or indentured labourers released from the slave ships. They came from east and central Africa and Madagascar, but it appears fairly certain that under the conditions of slavery and indenture they were unable to retain any tribal organisation (Fauvel, 1997).

Kinship structures have been described as 'matrifocal' indicating that the mother is the focal point of the family with the 'husband'. who may or may not be the father of the children, occupying a somewhat peripheral position in the domestic unit (Benedict, 1966). Marriage is the ideal form of union, but is often not achieved because of economic and prestige factors. An alternate form of stable union-living en ménage -has become institutionalised though not idealised (approximately $43 \%$ of children were born outside of marriage in 1959 and $76 \%$ in 1994). Consequently, many men are left with no responsibility in raising the family or spending time with their children.

\section{The health services}

The health services in the Seychelles are free of charge to every citizen. including medicine. Most of the doctors are expatriates. There is no medical school or university on the islands.

\section{Psychiatric services}

There is, at present, one psychiatrist working on the islands along with two staff doctors. The department also includes one clinical psychologist, three occupational therapy assistants and 16 permanent staff nurses with on-the-job psychiatric training. Additionally, one or two nurses are on short rotations from the general nursing staff. There is no psychiatric social worker, but the hospital-based social worker provides services to the department. There are two community psychiatric nurses attached to the unit working in liaison with the primary health care team.

The psychiatry department is located in Victoria Hospital. Victoria is the only general hospital with the specialist services to meet the national health needs. The department runs an acute unit with a provision for 16 adult patients. There are 12 beds in a dormitory equally divided for males and females with two side rooms. There are also two security rooms for confining acutely disturbed and dangerous patients.

Les Cannelles is a peripheral mental hospital of a high-walled one storey building with a Victorian styling built at the turn of this century. It is about $23 \mathrm{~km}$ from the main hospital. Most of the patients suffer from chronic schizophrenia or have severe learning disabilities. Some patients 
have been in-patients for decades, either abandoned by their families or because they are unable to live independently.

\section{Out-patient services}

The department runs two out-patient clinics daily, including one consultant clinic. At least 10 patients, including new and old, are booked for each clinic. New patients are generally referred from community-based district clinics as a part of the primary health care system. There are 12 such clinics on Mahé, two on Praslin, and one each on La Digue and Silhouette. Although the local language is Creole, an interpreter is available whenever necessary. However, most people can speak either English or French.

About half of the patients have co-existing alcohol or drugs misuse (cannabis) problems, complicating diagnosis and treatment of underlying psychotic disorders.

\section{Therapeutic options}

The country has its own national drug formulary with short-listed items of most essential drugs. Non-formulary drugs can be obtained through a drug committee only if formulary drugs are not indicated or are ineffective based on the individual situation. Obviously, we work with a limited range of psychotropic drugs, mainly of firstgeneration, that often tend to limit expected therapeutic achievements.

Clinicians use an eclectic approach involving pharmacological, psychological and behavioural therapies.

\section{Drug and alcohol unit}

About half of the psychiatric admissions are due to alcohol-related problems. This reflects the high alcohol consumption in Seychelles. In 1989, a population-based health survey indicated that $73 \%$ of men aged $25-64$ years reported occasional or regular drinking, of both commercial beverages and indigenous drinks (Bovet et al, 1991). The calculated annual alcohol intake per capita of those aged 25-64 years was 26.4 litres per man and 3.5 litres per woman. It has been suggested that this high alcohol consumption contributes to the high incidence of dilated cardiomyopathy among men (Pinn \& Bovet, 1991).

The acute ward also functions as a detoxification unit and provides group therapy for patients with alcohol dependency, and assesses patients' suitability for entry into a rehabilitation programme run by the Drug and Alcohol Rehabilitation Centre. The centre has only recently been established following heightened awareness of the magnitude of the substance misuse problem in the country.

\section{Community mental health care}

Usually the patients are followed up after their discharge either in the psychiatric out-patient clinics or in the district clinics where a community psychiatric nurse (CPN) pays regular visits. The CPN functions as a direct link between the psychiatric department and the community health care team headed by the general practitioner. The CPN sensitises colleagues and other community agents to the psychosocial aspects of mental health. As well as this he or she conducts home visits together with district health workers for elderly mentally ill, counsels the families of individuals with mental disorder and assists in identifying cases for appropriate referral.

\section{Forensic psychiatry}

The requirement of high security measures for mentally abnormal offenders are yet to be recognised. Patients are confined either in the Les Cannelles Hospital or in the general prison. Usually patients are brought to the out-patient department for follow-up accompanied by a prison guard.

\section{Legislation}

The present Mental Health Act is based on the British colonial Mental Treatment Ordinance of 1906. It is quite out of date. Currently the Mental Health Act is under review. Most patients are brought to hospital by the police on court orders for psychiatric assessment. Only the family can apply for a court order to detain a subject in the psychiatric unit. The detention is passed primarily for 14 days, but this can be extended on

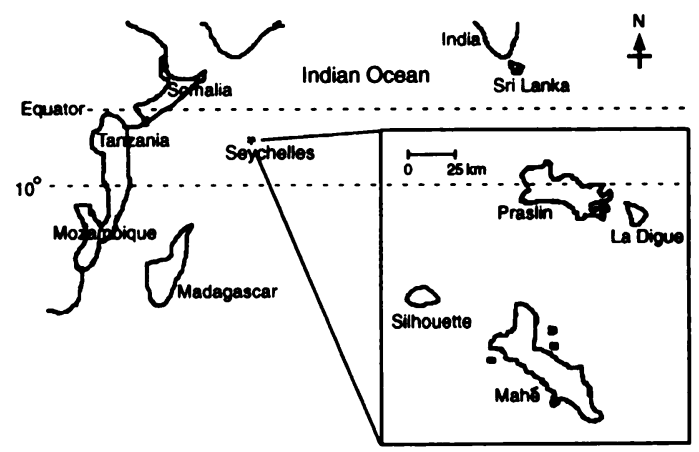

Fig. 1. The Seychelles; insert, the four main islands. 
request by the psychiatrist depending on clinical situation.

More likely the tourist industry has a significant implication in shaping all government policies.

Professional and academic isolation is quite pressing, there were three practising psychiatrists when I started work in the Seychelles, but six months later this was reduced to only one. This is often the case since the service depends on expatriates. The absence of peer review is often frustrating in the sense that it does not really ensure a good quality of care. Further isolation is attributable to unavailability of psychiatric journals. The situation has improved with access to the Internet in the hospital library. Having said all this, working in Seychelles is rewarding - in the sense that being a small place with a very small population makes it possible to meet patients almost every day in the town or on the street. They always greet me warmly without any pretensions. Whenever they see me they glow in joy as though they meet a trusted friend.

\section{References}

BENEDICT. B. (1966) People of the Seychelles. Overseas Research Publication N14. pp. 1-73. London: HMSO.

Bovet, P., Rosale. D., Shamlaye. C., et al (1991) The Seychelles Cardiovascular Diseases Survey 1989. Soztal und Praventivmedizin, 36 (suppl. 1), 53-57.

FAUVEL, A. A. (1997) Unpublished Documents on the History of the Seychelles Anterior to 1810. pp.112-115. Victoria, Seychelles: Government Printing Office.

PINN, G. \& BOVET, P. (1991) Alcohol-related cardiomyopathy in the Seychelles. Medical Joumal of Australia. 158. 529-532.

\section{Promoting Mental Health Internationally}

Editors: Giovanni de Girolamo, Leon Eisenberg, David Goldberg and John Cooper

To mark the retirement of Dr Norman Sartorius in 1993 from his post as Director of the Division of Mental Health of the World Health

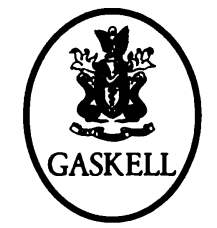
Organisation, the editors (all long-standing advisors and collaborators with the WHO programme) have brought together contributions from a mixture of advisors, collaborators and WHO staff members. The chapters provide descriptions and commentaries on the main aspects of the past 30 years of the WHO programme in mental health. The major topics and issues include the cross-cultural epidemiology and outcome of persons with serious mental illnesses, cross-cultural aspects of problems related to the misuse and control of alcohol and drugs of dependency, the role of psychiatry in primary care, and the development of a 'common language' for psychiatrists and mental health workers.

July 1999, Hardback, 200pp, ISBN 1901242 37 4, £25.00

Available from Book Sales, Royal College of Psychiatrists, 17 Belgrave Square, London SWIX 8PG

Tel +44 (0) 1712352351 (extension 146) $9.30 \mathrm{am}-2$ pm, Fax +44 (0) 1712451231

http://www.rcpsych.ac.uk 